\title{
2629. Ultrasound spectral analysis-based assessment of macular areas in patients with age related macular degeneration
}

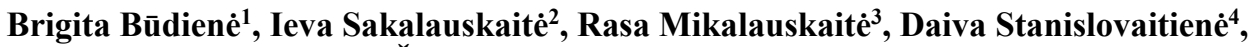 \\ Jurgis Trumpaitis ${ }^{5}$, Dalia Žaliūniené ${ }^{6}$ \\ $1,4,5,{ }^{6}$ Hospital of Lithuanian University of Health Sciences Kaunas Clinics Eye Clinic, Kaunas, Lithuania \\ ${ }^{2,3}$ Lithuanian University of Health Sciences, Kaunas, Lithuania \\ ${ }^{1}$ Corresponding author \\ E-mail: ${ }^{1}$ brigitabudiene@yahoo.com, ${ }^{2}$ iewaskl@gmail.com, ${ }^{3}$ rasa.mikalausk@gmail.com, \\ 4daivastanislovaitiene@yahoo.com,5j.trumpaitis@gmail.com, ${ }^{6}$ dalia.zaliuniene@lsmuni.lt
}

Received 6 January 2017; received in revised form 2 April 2017; accepted 4 April 2017 DOI https://doi.org/10.21595/jve.2017.18160

Check for updates

\begin{abstract}
Age-related macular degeneration (AMD) is the leading cause of irreversible vision loss in people aged 50 and older in the developed world. Early detection and treatment of AMD play the key role in helping patients at high risk for developing exudative to maintain their vision or slow down the progression of the disease. In this paper, the new technique for AMD evaluation using ultrasound spectral analysis is presented. Our aim was to compare B scan ultrasound signals backscattered from healthy tissues of macular area with signals from nonexudative and exudative AMD areas. In case-control study of 64 patients (144 tissues) we compared 82 cases of healthy tissue of macular area (I group) with 35 cases of nonexudative AMD (II group) and 30 cases of exudative AMD (III group) using B scan ultrasound. Estimated results showed that B scan amplitude and spectral intercept are informative to distinguish healthy tissues of macular area from AMD and spectral slope spectral, momentary bandwidth allow us to distinguish forms of AMD (nonexudative and exudative).We suggest that ultrasound spectral analysis is noninvasive, widely available, easy-to-use and less expensive method which can be used as an additional diagnostic tool in AMD detecting and differentiating when there are no possibilities to use more specific examination.
\end{abstract}

Keywords: ultrasound, age-related macular degeneration, spectral analysis, radiofrequency signals.

\section{Introduction}

Age-related macular degeneration (AMD) is a degenerative disorder of the central retina and represents the leading cause of severe visual impairment in the elderly population of industrialized societies [1]. Epidemiological studies estimate that the prevalence of AMD in Australia, Europe and North America is $0.2 \%$ in 55-64 year old patients and it increases to $13 \%$ in the age group of 85 years [2]. The disease is more common in Caucasian individuals than in pigmented races [3].

AMD typically presents with distortion of straight lines or edges, rapid onset of visual loss, and/or a blind spot in central or paracentral visual field [4]. A main cause of severe vision loss due to the disease is the development of choroidal neovascularization (CNV), leading to the exudative form of AMD It is therefore crucial that development of a new CNV be detected as early as possible, preferably before the development of a full-blown lesion which has already led to loss of letters, lines, and quality of life [5].

Treatment of exudative AMD may involve the use of anti-VEGF therapy, thermal laser treatment or photodynamic therapy. In patients presenting with $\mathrm{CNV}$, treatment with intravitreal injections of anti-vascular endothelial growth factor (VEGF) agents may improve visual acuity (VA) by three lines or more in $30-40 \%$ of patients and may prevent deterioration of visual acuity [6]. However, treatment of exudative AMD generally reduces but does not eliminate the risk of severe vision loss. 
Evaluation, detection and treatment of AMD play the key role in helping patients at high risk for developing exudative AMD to maintain their vision or slow down the progression of the disease. There are tests that are widely used in diagnosis as initial tests for AMD Table 1 and other imaging modalities can subsequently be used for further analysis Table 2 [7].

Table 1. Initial tests for primary diagnosis of AMD

\begin{tabular}{|c|c|c|}
\hline Tests & $\begin{array}{c}\text { Description } \\
\begin{array}{c}\text { Visual acuity } \\
\text { (VA) }\end{array}\end{array}$ & $\begin{array}{c}\text { One of the first signs or symptoms of visual loss in the early, non-neovascular stages } \\
\text { of AMD, may be a reduction in reading rate, and near VA is a good predictor of } \\
\text { reading rate [8]. As AMD progresses both near VA and reading rate reduce. It is } \\
\text { thought that if near VA is a great deal worse than distance VA, a scotoma is } \\
\text { impending near vision [9]. This method, while having the advantage of being easily } \\
\text { accessible, has not been proven in the literature [5]. }\end{array}$ \\
\hline $\begin{array}{c}\text { Amsler grid } \\
\text { test }\end{array}$ & $\begin{array}{c}\text { It can be used daily as per instructions to test for symptoms of macular degeneration } \\
\text { which can include one or more signs like distortion where straight lines appear wavy } \\
\text { or bent, dark patches or empty spaces appearing in the centre of vision [10]. } \\
\text { However, it was found that the sensitivity of the test ranged from 0.34 to 1.0 and its } \\
\text { specificity ranged from 0.85 to 1.0 [11]. }\end{array}$ \\
\hline $\begin{array}{c}\text { Color fundus } \\
\text { photography }\end{array}$ & $\begin{array}{c}\text { Gold standard for AMD screening and is a rapid way to look for soft drusen, the } \\
\text { earliest sign of AMD [12]. A digital fundus camera is used to capture an image of the } \\
\text { interior of the eye, including the retina, optic disc, and macula [7]. }\end{array}$ \\
\hline $\begin{array}{c}\text { Color contrast } \\
\text { sensitivity test }\end{array}$ & $\begin{array}{c}\text { Testing basic aspects of vision such as contrast sensitivity is more likely to reflect an } \\
\text { alteration of retinal function in early AMD [13]. Although acuity testing is simple to } \\
\text { implement in a clinical setting, it does not give exclusive information on retinal } \\
\text { function in early AMD when changes in VA are minimal } \\
\text { (two letter loss, or logMAR 0.04) [14]. }\end{array}$ \\
\hline
\end{tabular}

Table 2. Tests for further and more specific analysis of AMD

\begin{tabular}{|c|c|}
\hline Tests & Description \\
\hline $\begin{array}{l}\text { Fundus } \\
\text { Autofluorescence } \\
\text { (FAF) Imaging }\end{array}$ & $\begin{array}{l}\text { It is an in vivo imaging method for metabolic mapping of naturally or } \\
\text { pathologically occurring fluorophores of the ocular fundus [7]. FAF imaging may } \\
\text { be used to screen early AMD [15]. }\end{array}$ \\
\hline $\begin{array}{l}\text { Opti } \\
\text { Tom }\end{array}$ & $\begin{array}{c}\text { OCT functions as a type of optical biopsy, providing information on retinal } \\
\text { pathology in real time, with a resolution vastly better than magnetic resonance } \\
\text { imaging (MRI) or ultrasound. A major strength of SD-OCT over other imaging } \\
\text { modalities is its ability to capture 3D-volumetric information about the pathologies } \\
\text { [7]. }\end{array}$ \\
\hline $\begin{array}{r}\text { Optical Col } \\
\text { Tomogr } \\
\text { Angiogr } \\
\text { (OCT }\end{array}$ & $\begin{array}{r}\text { OCT angiography (OCTA) is an advan } \\
\text { amplitude or phase decorrelation technol } \\
\text { volumetric scanning to detect erythrocyte } \\
\text { of blood vessels in vivo, without the }\end{array}$ \\
\hline $\begin{array}{l}\text { Angiography } \\
\text { Fluorescein (FA) } \\
\text { and } \\
\text { Indocyanine Green } \\
\quad \text { (ICG) }\end{array}$ & $\begin{array}{l}\text { Angiography, both fluorescein and indocyanine green (ICG), is useful test to look } \\
\text { for choroidal neovascularization. A small gage needle attached to a plastic catheter } \\
\text { is inserted into a vein, usually in the arm, and a fluorescent dye is injected through } \\
\text { the catheter and enters the bloodstream. As the dye enters the blood vessels of the } \\
\text { eye, a series of pictures are taken of the retina using a fundus camera. Special filters } \\
\text { matched for the excitation and emission wavelengths of the dye are placed in a } \\
\text { beam splitter so that only the fluorescence of the dye in the blood vessels is } \\
\text { visualized against the dark remainder of the background retinal tissue [7]. }\end{array}$ \\
\hline
\end{tabular}

However, sometimes there are no possibilities to use these diagnostic tools. In some cases, ophthalmoscopy, fundus photography, OCT and other diagnostic methods are impossible due to opacification of light transmitting media or other reasons like walking disability after stroke, cardiovascular, neurological and oncological diseases, also multiple organ failures.

Because overlying opacities have no effect on the examining ultrasonographic frequencies, ultrasound has the unique ability to depict the nature of intraocular pathology when the media are 
optically opaque [18].

Ultrasonic methods stand out in ophthalmology with good informative value among the noninvasive methods. Early detection of lesions and accurate diagnosis leads to effective assistance [19]. During the past two decades, improvements in the resolution and reliability of instrumentation and techniques have allowed A-scan and B-scan ultrasonography to join direct visualization, fluorescein angiography, and radioactive phosphorus testing as primary diagnostic modalities in the evaluation of eye [18].

In the last decade, ultrasound probes with higher frequency and higher resolution have been commercialized, such as the $20 \mathrm{MHz}$ probe used for eye posterior pole studies. Frequency is important in ultrasound because it is directly related to resolution and inversely related to penetration of ultrasonographic images [20].

In this study, we were investigating a noninvasive ultrasound imaging method which is widely available not only in tertiary-level hospitals, easy-to-use and less expensive than other imaging methods in order to detect AMD as early as possible and achieve better outcome in treatment. Our aim was to compare B scan ultrasound signals backscattered from healthy tissues of macular area with signals from nonexudative and exudative AMD areas.

\section{Methods and data}

Patients, who came to Hospital of Lithuanian University of Health Sciences Kaunas Clinics Eye Clinic from February 1st, 2016 to August 31st, 2016 were included in the study. We performed case-control study of 64 patients (144 tissues). We examined 82 cases with healthy tissue of macular area as a control group, 32 cases with nonexudative AMD and 30 cases with exudative AMD. We excluded eyes with glaucoma, diabetic maculopathy, high degree myopia, inflammatory retinal and choroidal diseases.

Distribution of patients by sex in 144 cases of examined tissues was 92 women and 52 men in total. Average age was $72.82 \pm 8.83$ years. All participants were above 50 years old. The youngest patient was 50 years old and the oldest -90 years old.

Before echography using B mode Mentor ${ }^{\mathrm{TM}}$ Advent ultrasonic diagnostic imaging system all patients underwent comprehensive ophthalmological examination. Color fundus photography, optical coherence tomography imaging was used to evaluate AMD and differentiate healthy eyes, exudative and nonexudative AMD eyes (Fig. 1). Best-corrected visual acuity (measured in decimals from 0.1 to 1.0 ) was evaluated using Landolt'sings (C optotypes) by Snellen test types at a 5 meter distance from the chart.

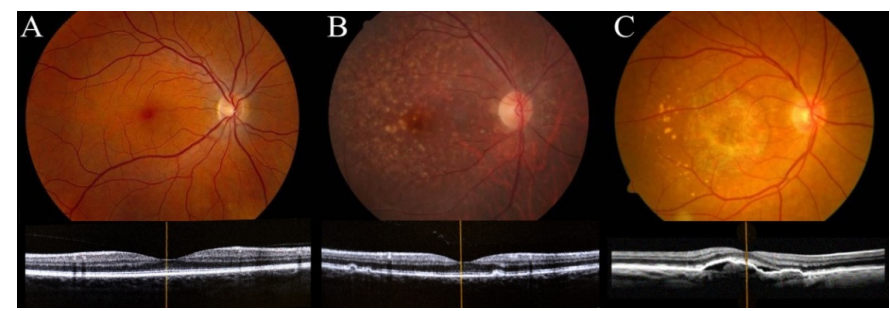

Fig. 1. Color fundus photographs of the human retina performed with OPHTEK Visucam (top) and High-quality spectral-domain optical coherence tomography (SDOCT) images of the macula (bottom):

a) healthy eye, b) nonexudative AMD, c) exudative AMD

The hardware and software system used for acquisition of ultrasound B scan raw signals is described by Jurkonis and others [21].

The ultrasound B scan system is Mentor (Advent, Norwell, MA), with mechanical scanning transducer of $12 \mathrm{MHz}$, which is an original system supplemented with signal acquisition system [22]. System assures acquisition of raw ultrasound diagnostic signals with $250 \mathrm{MHz}$ sampling frequency and 8 bits amplitude resolution. B scan raw signals were stored into database on 
computer hard disc and analyzed off-line. Analysis was performed by ophthalmologist using NICDIT v1.2 software. B scan raw signals were loaded into software and reviewed [23]. Two areas were investigated: healthy tissue area of macular zone and area of AMD zone. Both regions were of the same length $1.5 \mathrm{~mm}$ in all analyzed cases. Regions of interest were selected manually by two of the authors RM and IS Fig. 2. If there was not complete agreement between researchers these cases were excluded.

We analyzed radiofrequency row signals using the following five parameters: B scan amplitude $V$, spectral intercept $\mathrm{dB}$, average instantaneous bandwidth $\mathrm{MHz}$, spectral slope $\mathrm{dB} / \mathrm{MHz}$ and spectral momentary bandwidth $\mathrm{MHz}$ of approximated backscattered spectra. The amplitude of a radio frequency echo signal distribution equals to the sum of the signals from each reflecting point in the radiation line. Power spectrum of the echo signal is calculated using the discrete Fourier transformation [23]. NICDIT v1.2 software algorithms were used to analyze the raw radio frequency signals from selected regions [24].

Statistical analysis was performed using the computer program SPSS/W 19.0 (Social sciences statistical package program for Windows, Inc., Chicago, Illinois, USA). T test and the Mann-Whitney $U$ test were used for the comparison of all groups. A statistically significant difference was considered if $p<0.05$ and the confidence interval was set as $95 \%$.
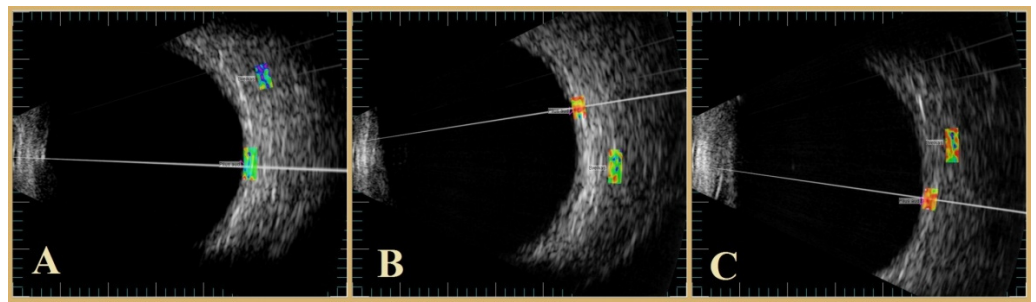

Fig. 2. Photographs of the human retina performed with B scan ultrasound: a) healthy eye, b) nonexudative AMD, c) exudative AMD

\section{Results}

Preliminary conclusions can be made after study of 82 cases with healthy tissue area compared to 32 cases with nonexudative AMD and 30 cases with exudative AMD. Characteristics of separate groups are shown in Table 3.

Table 3. The characteristics of patients with AMD and healthy subjects included to the study

\begin{tabular}{|c|c|c|c|}
\hline \multirow{2}{*}{ Characteristic } & \multicolumn{3}{|c|}{ Results } \\
\cline { 2 - 4 } & Healthy tissues of macular area & Nonexudative AMD & Exudative AMD \\
\hline Men, $n(\%)$ & $30(36.59)$ & $13(40.63)$ & $9(30)$ \\
\hline Women, $n(\%)$ & $52(63.41)$ & $19(59.37)$ & $21(70)$ \\
\hline Age, min-max $($ mean \pm SD) & $50-90(71.39 \pm 9.26)$ & $56-87(75.34 \pm 7.44)$ & $62-84(76.73 \pm 6.13)$ \\
\hline
\end{tabular}

\subsection{B scan amplitude, $V$}

The analyses of B scan amplitude showed a significant difference between control group compared to nonexudative AMD group and exudative AMD group (mean difference $-0.022 \pm 0.007, p=0.004$; mean difference $-0.032 \pm 0.007, p<0.001$, respectively). We didn't obtain significant difference of the amplitude comparing nonexudative AMD group to exudative AMD group (mean difference $0.01 \pm 0.008, p=0.68$ ). The largest B-scan amplitude was observed in exudative AMD group $(0.088 \pm 0.041 \mathrm{~V})$, the middle B-scan amplitude - in nonexudative AMD group $(0.078 \pm 0.031 \mathrm{~V})$ and the smallest value was found in healthy tissues area of control group $(0.056 \pm 0.029 \mathrm{~V})$ (Fig. 3). 


\subsection{Spectral intercept, $\mathrm{dB}$}

Significant differences in the mean values of mean spectral intercept between control group and nonexudative AMD group (mean difference $-5.78 \pm 1.2, p<0.001$ ), also between control group and exudative AMD (mean difference $-3.23 \pm 1.22, p=0.028$ ) were found. However, there were no significant difference between nonexudative and exudative AMD group (mean difference $2.55 \pm 1.46, p=0.246)$. The highest value of spectral intercept was determined in nonexudative group $(-4.02 \pm 5.55 \mathrm{~dB})$ and the lowest value of spectral intercept was detected in control group $(-9.8 \pm 5.57 \mathrm{~dB})$ (Fig. 4).

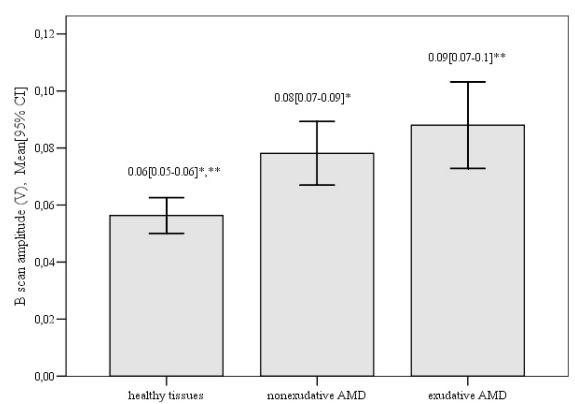

Fig. 3. Mean $B$ scan amplitude in different groups $\left({ }^{*} p=0.004 ; * *<0.001\right)$

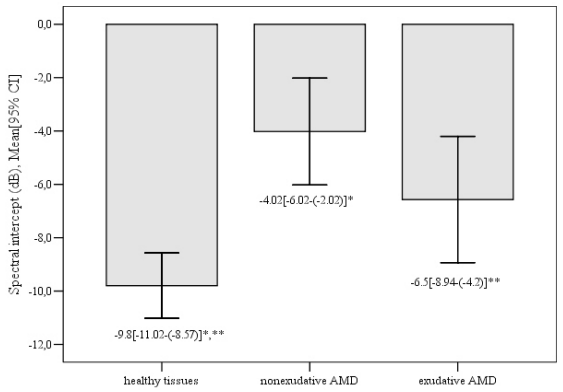

Fig. 4. Mean spectral intercept in different groups $\left({ }^{*} p<0.001 ; * * p=0.028\right)$

\subsection{Average instantaneous bandwidth, $\mathrm{MHz}$}

We estimated that average instantaneous bandwidth had similar results in comparing healthy tissue area with areas of AMD - mean difference between control and nonexudative AMD group was $0.02 \pm 0.06, p>0.05$, between control and exudative AMD group $-0.08 \pm 0.06, p=0.658$. Also, no significant difference was estimated between nonexudative and exudative AMD groups (mean difference $0.1 \pm 0.07, p=0.568$ ). The highest value of this parameter was established in nonexudative AMD group $(1.13 \pm 0.27 \mathrm{MHz})$ and the lowest - in exudative AMD group $(1.04 \pm 0.17 \mathrm{MHz})$.

\subsection{Spectral slope, $\mathrm{dB} / \mathrm{MHz}$}

The analyses of mean spectral slope showed statistically significant differences between control and nonexudative AMD group (mean difference $0.32 \pm 0.11, p=0.012$ ), also between nonexudative AMD and exudative AMD group (mean difference $0.36 \pm 0.13, p=0.021$ ). There were no significant mean differences between control and exudative AMD group (mean difference $0.05 \pm 0.11, p>0.05)$. We determined that the highest spectral slope was in healthy tissues area of control group $(-2.08 \pm 0.5 \mathrm{~dB} / \mathrm{MHz})$ and the lowest spectral slope was found in nonexudative AMD group (-2.4 $\pm 0.48 \mathrm{~dB} / \mathrm{MHz})$ (Fig. 5).

\subsection{Spectral momentary bandwidth, $\mathrm{MHz}$}

We estimated that results of comparing spectral momentary bandwidth between control and nonexudative AMD groups, also between nonexudative and exudative AMD groups were statistically significant (mean difference $0.36 \pm 0.15, p=0.008$; mean difference $0.45 \pm 0.19$, $p=0.045$, respectively). We did not find significant difference between control and exudative group (mean difference $0.09 \pm 0.16, p=0.295$ ). The highest value of spectral momentary bandwidth was detected in patiens with exudative AMD (10.29 \pm 0.73$)$ and the lowest value was detected in patiens with nonexudative AMD (9.84 \pm 0.65$)$ (Fig. 6).

Summary of results characterizing parameters extracted from radio frequency of ultrasound 
signals, defined as mean and standard deviation, are presented in Table 4.

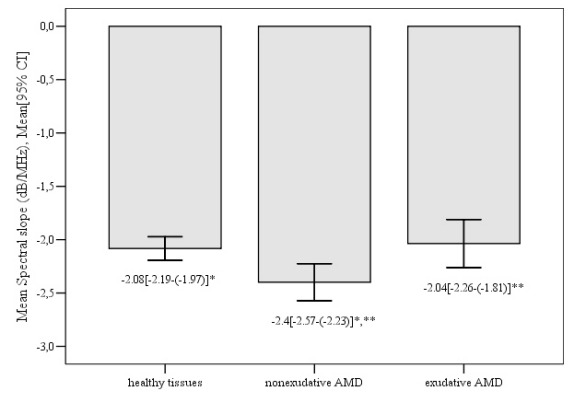

Fig. 5. Mean spectral slope in different groups $(* p=0.012 ; * * p=0.021)$

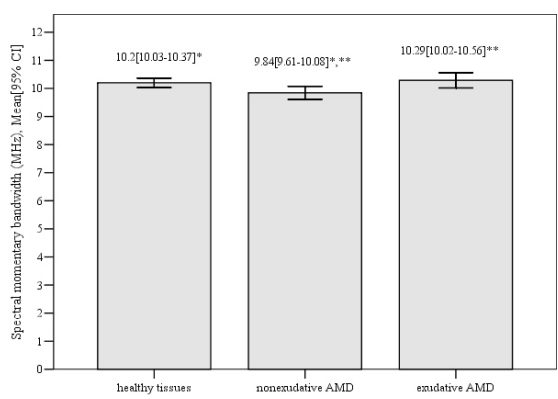

Fig. 6. Mean spectral momentary bandwidth in different groups $(* p=0.008 ; * * p=0.045)$

Table 4. Differentiation parameters (mean, std. deviation) of B scan ultrasound signals backscattered from intraocular tissues

\begin{tabular}{|c|c|c|c|}
\hline \multirow{2}{*}{ Parameter } & \multicolumn{3}{|c|}{ Area in tissues } \\
\cline { 2 - 4 } & $\begin{array}{c}\text { Healthy tissues } \\
\text { of macular area }\end{array}$ & $\begin{array}{c}\text { Nonexudative } \\
\text { AMD }\end{array}$ & $\begin{array}{c}\text { Exudative } \\
\text { AMD }\end{array}$ \\
\hline B scan amplitude, $V$ & $0.06 \pm 0.03$ & $0.08 \pm 0.03$ & $0.09 \pm 0.04$ \\
\hline Spectral intercept, dB & $-9.8 \pm 5.57$ & $-4.02 \pm 5.55$ & $-6.5 \pm 6.34$ \\
\hline Average instantaneous bandwidth, $\mathrm{MHz}$ & $1.11 \pm 0.33$ & $1.13 \pm 0.27$ & $1.04 \pm 0.17$ \\
\hline Spectral slope, dB/MHz & $-2.08 \pm 0.5$ & $-2.4 \pm 0.48$ & $-2.04 \pm 0.6$ \\
\hline Spectral momentary Bandwidth, $\mathrm{MHz}$ & $10.2 \pm 0.76$ & $9.84 \pm 0.65$ & $10.29 \pm 0.73$ \\
\hline
\end{tabular}

\section{Discussion}

Ultrasound B scan has proven to be a precise and valid alternative aiding in the prompt and early diagnosis in cases of ocular trauma where opacification of the light conducting media has occurred. This is especially important in a setting where the overall burden of trauma on healthcare in general and on emergency department in particular is increasing every year [25].

Trumpaitis et al. study has shown that the lower amplitude, lower spectral intercept, high spectral slope and high momentary bandwidth are typical for choroidal melanoma if compared with hemangioma or healthy tissues. This allows us to distinguish healthy tissues from the abnormal tumor tissues and also to identify and differentiate choroidal melanoma from hemangioma [23].

Trumpaitis et al. obtained results in their study that showed there was statistically significant difference between the radio frequent ultrasound signal parameters (amplitude, spectrum slope, spectrum intercept and momentary bandwidth) in the healthy tissue area and in the area with the intraocular tumor - melanoma before and after treatment. According to this research, tested parameters allows us to distinguish healthy tissues from the abnormal tumor tissues and also to identify choroidal melanoma [24].

Ultrasound imaging USI allows measurement of blood flow velocities BFVs in the retrobulbar arteries [26]. In patients with AMD, USI thus allows for the characterization of BFV changes in all retrobulbar arteries after a single intravitreal injection of bevacizumab [28]. In Bonin, et al. study ultrasound imaging was performed using a Sonoline Elegra Advanced System (Siemens AG, Erlangen, Germany) equipped with a linear transducer type $7.5 \mathrm{~L} 409 \mathrm{MHz}$. The researchers highlighted an unexpected effect of intravitreal ranibizumab on retrobulbar arteries in patients with exudative AMD, consisting of reduced blood flow velocity in the posterior ciliary, central retinal and ophthalmic arteries, suggesting that anti-angiogenic therapy could impair the native choroidal and retinal vascular circulations [27].

To the best of our knowledge, this is the first study trying to figure out B-scan spectral analysis 
possibilities for detecting age related macular degeneration. Our study has shown that amplitude, spectral intercept, spectral slope and momentary bandwidth are different in AMD tissues if compared with healthy tissues. This allows us to distinguish healthy tissues from AMD affected tissues and also to identify this retinal disease.

B. Budiene - participants data examination, manuscript preparation (drafted manuscript). D. Stanislovaitiene - participants' data examination, helped to draft manuscript. I. Sakalauskaite participant's data analysis, statistical analysis (has made analysis and interpretation of data). R. Mikalauskaite - participant's data analysis, statistical analysis (has made analysis and interpretation of data). J. Trumpaitis - ultrasound examination and data interpretation. D. Zaliuniene - has made substantial contributions to conception and design, revised manuscript critically. All authors read and approved the final manuscript.

\section{Conclusions}

The timeframe from appearance of symptoms to diagnosis and treatment AMD is not ideal. Accordingly, several methods have been proposed for early detection of CNV, which may be unnecessarily delayed [6]. In the present study, we were investigating clinical uses of ultrasound imaging and spectral analysis in order to detect AMD and start effective treatment as early as possible. Estimated results showed a statistically significant difference between the radio frequency ultrasound signal parameters in comparison of healthy tissues area with tissues affected with nonexudative and exudative AMD.

Analyzing values of B scan amplitude, spectral intercept, spectral slope and spectral momentary bandwidth we revealed a significant difference between healthy tissues comparing to nonexudative AMD tissues ( $p=0.004, p<0.001, p=0.012$ and $p=0.008$, respectively). B scan amplitude and spectral intercept showed significant differences between control group and exudative AMD group ( $p<0.001, p=0.028$, respectively).

Two of the parameters - spectral slope and spectral momentary bandwidth were the ones to show a significant difference between nonexudative and exudative $\operatorname{AMD}(p=0,021, p=0.045$, respectively).

To summarize B scan amplitude and spectral intercept are informative to distinguish healthy tissues of macular area from AMD (nonexudative and exudative). Spectral slope and spectral momentary bandwidth allow us to distinguish forms of AMD. Spectral analysis can be used as an additional diagnostic tool for AMD and for differentiating nonexudative from exudative AMD. We suggest that this non-invasive ultrasound expert system provides the new opportunities in ophthalmology, allowing us to detect and differentiate AMD when other diagnostic methods are unavailable or we cannot use them due to complicated patient condition (for ex., opacification of light transmitting media, disability after stroke and other cardiovascular diseases that cause disability to move). Further investigation including more patients should be done in order to evaluate the options of spectral analysis.

\section{References}

[1] Lim L. S., Mitchell P., Seddon J. M., Holz F. G., Wong T. Y. Age-related macular degeneration. Lancet, Vol. 379, Issue 9827, 2012, p. 1728-1738.

[2] Smith W., Assink J., Klein R., Mitchell P., Klaver C. C., Klein B. E. Risk factors for age-related macular degeneration: pooled findings from three continents. Ophthalmology, Vol. 108, 2001, p. 697-704.

[3] Michalska-Małecka K., Kabiesz A., Nowak M., Śpiewak D. Age related macular degeneration challenge for future: pathogenesis and new perspectives for the treatment. European Geriatric Medicine, Vol. 6, 2015, p. 69-75.

[4] Boniface K. S., Shokoohi H., Doctor S., Pourmand A., McKay M. P. Acute subretinal hemorrhage and exudative age-related macular degeneration: the role of bedside ocular ultrasound in ED diagnosis 
and management. American Journal of Emergency Medicine, Vol. 27, Issue 3, 2009, https://doi.org/10.1016/j.ajem.2008.07.011.

[5] Schwartz R., Loewenstein A. Early detection of age related macular degeneration: current status. International Journal of Retina and Vitreous, 2015, https://doi.org/10.1186/s40942-015-0022-7.

[6] Heier J. S., Brown D. M., Chong V. Intravitreal aflibercept (VEGF trap-eye) in wet age-related macular degeneration. Ophthalmology, Vol. 119, 2012, p. 2537-2548.

[7] Kanagasingam Y., Bhuiyan A., Abràmoff M. D., Smith R. T., Goldschmidt L., Wong T. Y. Progress on retinal image analysis for age related macular degeneration. Progress in Retinal and Eye Research, Vol. 38, 2014, p. 20-42.

[8] Lovie-Kitchin J., Feigl B. Assessment of age-related maculopathy using subjective vision tests. Clinical and Experimental Optometry, Vol. 88, 2005, p. 292-303.

[9] Lovie-Kitchin J. E., Devereaux J., Wells S., Sculpher K.-A. Multi-disciplinary low vision care. Clinical and Experimental Optometry, Vol. 84, 2001, p. 165-170.

[10] Amsler Grid. Macular Disease Foundation Australia, http://www.mdfoundation.com.au/resources/1/00_Amsler_Grid.pdf.

[11] Faes L., Bodmer N. S., Bachmann L. M. Diagnostic accuracy of the Amsler grid and the preferential hyperacuityperimetry in the screening of patients with age-related macular degeneration: systematic review and meta-analysis. Eye, Vol. 28, 2014, p. 788-796.

[12] Köse C., Sevik U., Gençalioglu O. Automatic segmentation of age-related macular degeneration in retinal fundus images. Computers in Biology and Medicine, Vol. 38, Issue 5, 2008, p. 611-619.

[13] Bird A. C. Therapeutic targets in age-related macular disease. Journal of Clinical Investigation, 2010, p. 3033-3041.

[14] Klein R., Wang Q., Klein B. E., Moss S. E., Meuer S. M. The relationship of age-related maculopathy, cataract, and glaucoma to visual acuity. Investigative Ophthalmology and Visual Science, 1995, p. 182-191.

[15] Framme C., Roider J., Sachs H. G., Brinkmann R., Gabel V. P. Noninvasive imaging and monitoring of retinal pigment epithelium patterns using fundus autofluorescence - review. Current Medical Imaging Reviews, Vol. 1, Issue 1, 2005, p. 89-103.

[16] Spaide R. F., Klancnik J. J. M., Cooney M. J. Retinal vascular layers imaged by fluorescein angiography and optical coherence tomography angiography. JAMA Ophthalmology, Vol. 133, Issue 1, 2015, p. 45-50.

[17] Nagiel A., Sadda S. R., Sarraf D. A promising future for optical coherence tomography angiography. JAMA Ophthalmology, Vol. 133, Issue 6, 2015, p. 629-630.

[18] Goldberg M. F., Hodes B. L. Ultrasonographic diagnosis of choroidal malignant melanoma. Survey of Ophthalmology, Vol. 22, 1977, p. 29-40.

[19] Paunksnis A., Barzdžiukas V., Kažys R., Raišutis R., Lukoševičius A., Paunksnis M., Janušauskas A., Marozas V., Jegelevičius D., Daukantas S., Kopsala S., Kurapkienė S., Kriaučiūnienė L., Jurkonis R. A non-invasive expert system for diagnosis of intraocular tumours: the system concept. Ultrasound, 2012, p. 66-72.

[20] Coleman D. J., Silverman R. H., Chabi A., Rondeau M. J., Shung K. K., Cannata J., Lincoff H. High-resolution ultrasonic imaging of the posterior segment. Ophthalmology, 2004, p. 1344-1351.

[21] Jurkonis R., Daukantas S., Janušauskas A., Lukoševičius A., Marozas V., Jegelevičius D. Synthesis of parametric map from raw ultrasound B-Scan data. Electronics and Electrical Engineering, Vol. 6, Issue 94, 2009, p. 109-112.

[22] Jurkonis R., Trumpaitis J., Šarkūnaitė D., Paunksnis A. Application of ultrasound radiofrequency analysis for intraocular tissues differentiation. Biomedical Engineering Conference, 2012.

[23] Trumpaitis J., Jurkonis R., Imbrasienė D., Grizickaitė A., Paunksnis A. Application of ultrasound spectral analysis for intraocular tissues differentiation. Journal of Vibroengineering, Vol. 16, Issue 7, 2014, p. 3586-3594.

[24] Trumpaitis J., Jurkonis R., Sakalauskaitė I., Paunksnis A. Application of ultrasound spectral analysis for choroidal melanomas before and after treatment analysis. Baltic Journal of Modern Computing, 2015, p. 55-71.

[25] Shazlee M. K., Ali M., Ahmed M. S., Hussain A., Hameed K., Lutfi I. A., Khan M. T. Diagnostic accuracy of ultrasound B scan using $10 \mathrm{MHz}$ linear probe in ocular trauma; results from a high burd. Pakistan Journal of Medical Sciences, Vol. 32, Issue 2, 2016, p. 385-388.

[26] Matthiessen E. T., Zeitz O., Richard G., Klemm M. Reproducibility of blood flow velocity measurements using colour decoded Doppler imaging. Eye, Vol. 18, 2004, p. 400-405. 
2629. ULTRASOUND SPECTRAL ANALYSIS-BASED ASSESSMENT OF MACULAR AREAS IN PATIENTS WITH AGE RELATED MACULAR DEGENERATION.

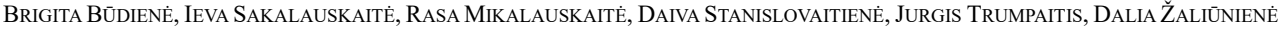

[27] Bonnin P., Pournaras J. A. C., Lazrak Z., Cohen S. Y., Legargasson J. F., Gaudrica, Levy B. I., Massinp Ultrasound assessment of short-term ocular vascular effects of intravitreal injection of bevacizumab (Avastin) in neovascular age-related macular degeneration. Acta Ophthalmologica, Vol. 88, 2010, p. 641-645.

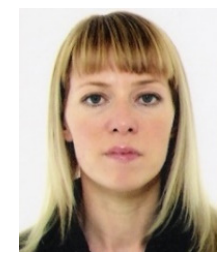

Brigita Būdienè received M.D. degree in Lithuanian University of Health Sciences Kaunas, Lithuania, in 2005. She finished ophthalmology residency in 2008 and currently she is Ph.D. student in Lithuanian University of Health Sciences Kaunas, Lithuania. Now she works at Hospital of Lithuanian University of Health Sciences Kaunas Clinics as a doctor of ophthalmology. Her current clinical and research interests include strabismus, ophthalmogenetics, retinal diseases.

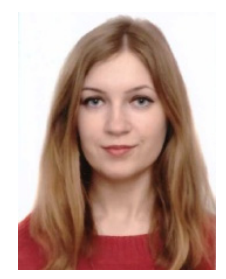

Ieva Sakalauskaitė currently is a fifth-year medicine student in Lithuanian University of Health Sciences. She is interested in ophthalmology. Her current research includes ultrasonography, optical coherence tomography angiography and other diagnostic tools for eye diseases.

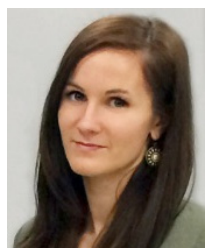

Rasa Mikalauskaitė currently is a fifth-year medicine student in Lithuanian University of Health Sciences. She is interested in ophthalmology. Her current research includes ultrasonography and other diagnostic tools for eye diseases.

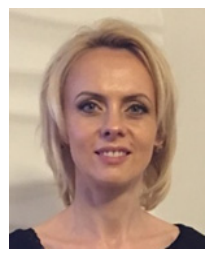

Daiva Stanislovaitienė received M.D. degree in Lithuanian University of Health Sciences Kaunas, Lithuania, in 2005. She finished ophthalmology residency in 2009 and received Ph.D. degree in Lithuanian University of Health Sciences Kaunas, Lithuania, in 2013. Now she works at Hospital of Lithuanian University of Health Sciences Kaunas Clinics as a doctor of ophthalmology. Her current clinical and research interests include anterior segment microsurgery, ophthalmogenetics, retinal diseases.

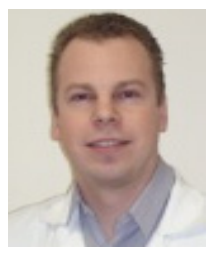

Jurgis Trumpaitis received M.D. degree in Lithuanian University of Health Sciences Kaunas, Lithuania, in 2006. He finished ophthalmology residency in 2010. He received Ph.D. degree in Lithuanian University of Health Sciences Kaunas, Lithuania, in 2015. Now he works at Hospital of Lithuanian University of Health Sciences Kaunas Clinics as a doctor of ophthalmology. His current research interests include analysis of ultrasonic tissue characterization of the eye, inflammatory eye diseases, ocularplastic.

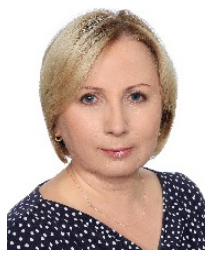

Dalia Žaliūnienė received M.D. degree in Lithuanian University of Health Sciences Kaunas, Lithuania, in 1986. She received Ph.D. degree in Lithuanian University of Health Sciences Kaunas, Lithuania, in 2006. Professor at Lithuanian University of Health Sciences from 2015. Now she works at Hospital of Lithuanian University of Health Sciences Kaunas Clinics as a doctor ophthalmologist. She is head in Hospital of Lithuanian University of Health Sciences, Ophthalmology department, One day surgical division. Her current clinical and research interests include anterior segment microsurgery, ophthalmogenetics, retinal diseases. 